\title{
Prevalence and antibiogram study of Staphylococcus aureus isolated from clinical and selected drinking water of Dutsin-Ma, Katsina state, Nigeria
}

\author{
Adesoji AT, Onuh JP, Bagu J, Itohan SA
}

Department of Microbiology, Federal University Dutsin-Ma, Nigeria.

\begin{abstract}
Background: Multidrug resistant Staphylococcus aureus in clinical and environmental samples is a global problem. Data comparing antibiogram of bacteria from these two sources in Nigeria is scarce. Therefore, this study compares antibiogram of isolates from both sources from Dutsin-Ma, Katsina State, Nigeria.

Methodology: A total of 120 and 150 clinical and aquatic samples respectively were collected for a five months period. Samples were analyzed for isolation of $S$. aureus using mannitol salt agar. Bacteria identification were carried out using standard biochemical characterization. Antibiogram of the isolates were determined using disc diffusion methods and comparison with Clinical Laboratory Standard Institute (CLSI)'s Standard.

Result: A total of 120 and 45 S. aureus were isolated from both clinical and aquatic samples respectively. Highest (100.0\%) resistance to cloxacillin was observed among isolates from each source. Clinical and aquatic isolates showed least resistance of $20.0 \%$ and $48.0 \%$ respectively to gentamicin. All isolated S. aureus (165) from this studies were multidrug resistant with different antibiotic resistant pattern.

Conclusion: This study revealed that multidrug resistance strains of $S$. aureus can be isolated from both clinical and drinking water sources, hence, a public health significance that calls for urgent attention by clinicians and public health workers.

Keywords: Clinical isolates, aquatic isolates, s. aureus, multi-drug resistant.

DOI: https://dx.doi.org/10.4314/ahs.v19i1.11

Cite as: Adesoji AT, Onuh JP, Bagu J, SA I. Prevalence and antibiogram study of Staphylococcus aureus isolated from clinical and selected drinking water of Dutsin-Ma, Katsina state, Nigeria. Afri Health Sci. 2019;19(1). 1385-1392. https:/ / dx.doi.org/10.4314/ abs.v19i1.11
\end{abstract}

\section{Introduction}

S. aureus, is a facultative aerobic, Gram-positive cocci which has an inherent ability to ferment carbohydrates, producing quite a number of pigmentation ranging from white to deep yellow (on mannitol salt agar). They are easily identified by detecting the presence of deoxyribonuclease (DNase), catalase enzymes and coagulase proteins produced by them. ${ }^{1}$

S. aureus has been implicated in many nosocomial infections ${ }^{2}$ including some invasive infections such as noso-

\section{Corresponding author: \\ Adesoji AT, \\ Department of Microbiology, \\ Federal University Dutsin-Ma, Nigeria. \\ Email: timmyayus2002@yahoo.com}

comial bacteremia and septicemia (sepsis). ${ }^{3}$ MRSA is a major public health concern and is responsible for both hospital-and community-associated infections worldwide. ${ }^{4,5,6,7,8,9}$ Although ubiquitous in nature, the occurrence and distribution of these organisms have been reported to be influenced by geographical location, type of hospital and studied population. ${ }^{1}$ Moreover, there are few studies in Nigeria that compare antibiogram of this bacterium based on these different criteria.

The presence of $S$. aureus from the environment, especially different types of water available for human consumption and/or recreation has also been reported, ${ }^{10,11,12}$ and may be regarded as one of the genera frequently isolated from water supplies as Heterotrophic Plate Count (HPC) bacteria. ${ }^{11,13}$

Available literature showed the isolation of $S$. aureus from water across the globe..$^{10,11,12,14,15,16,17,18}$ Conversely, there is,

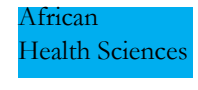

(C) 2019 Adesoji et al. Licensee African Health Sciences. This is an Open Access article distributed under the terms of the Creative commons Attribution License (https://creativecommons.org/licenses/BY/4.0), which permits unrestricted use, distribution, and reproduction in any medium, provided the original work is properly cited. 
however, a paucity of information on the isolation of $S$. aureus from Dutsin-Ma drinking water.

Researchers have reported that the presence of the organism in high concentrations in swimming pools ${ }^{17}$ and bathing beaches ${ }^{14}$ were associated with the skin and eye infections of the bathers. ${ }^{15,16}$ However only few studies have reported this phenomenon especially in Nigeria. Likewise, studies have also shown that most $S$. aureus isolated from bathing water came from their users themselves $^{17,18}$ and may therefore indicate a possible relationship between clinical and environmental (drinking water) isolates. Hence, this study seeks to compare the antibiotic resistance profiles of $S$. aureus isolated from both clinical and selected drinking water environments from DutsinMa, Katsina State, Nigeria.

\section{Materials and methods}

\section{Study area and sample location}

The study was carried out in the town of Dutsin-Ma, Dutsin-Ma local government area, Katsina State, Nigeria which lies between the geographic coordinates of $12^{\circ} 27^{\prime} 17^{\prime \prime N}, 7^{\circ} 29^{\prime} 29^{\prime \prime} E .^{19}$ The local government has an area of $527 \mathrm{~km}^{2}$ and has the Zobe Dam lying to the South of the town. ${ }^{20}$ Federal University Dutsin-Ma clinic and General hospital Dutsin-Ma were two hospitals selected for isolation of clinical $S$. aureus while drinking water samples were collected for aquatic $S$. aureus from selected wells, boreholes, tanks etc. from this same environment.

\section{Ethical approval}

Ethical approval was obtained from Federal University Dutsin-Ma clinic and Dutsin-Ma General Hospital. Informed consent was also obtained from patients sampled.

\section{Samples and samples collection}

A total of 120 clinical samples (from nasal, ear, pus, wound, and skin surfaces) were collected from patients from Federal university Dutsin-Ma clinic and General hospital Dutsin-Ma between April and August, 2016. Also, 150 water samples (comprising tap, borehole, tank, reservoir and well water from the water board, Abuja road, Kofa community, Federal University Dutsin-Ma students' hostel, and Doctors' campus, all in Dutsin-Ma) were aseptically collected for the purpose of this research during the same period.
Clinical samples were collected using sterile swap sticks while the water samples were collected using sterile sample bottles $(20 \mathrm{mls})$. All samples were transported within six hours of collection to the Laboratory of Department of Biological Sciences, Federal University Dutsin-Ma, Dutsin-Ma, Katsina State, Nigeria. Thereafter, samples were cultured on mannitol salt agar (MSA) for isolation of $S$. aureus.

\section{Bacteria isolation, identification and characteriza- tion}

Swap sticks used for clinical sampling were streaked on blood agar (to detect their hemolytic ability) and mannitol salt agar (MSA) in sterile petri dishes for isolation of $S$. aureus. Afterwards, plates were incubated at $37^{\circ} \mathrm{C}$ in an incubator. blood agar plates were observed after 24 hours, while the mannitol salt agar were observed after 48 hours incubation for visible growth. ${ }^{21}$ In order to obtain a distinct colony, bacteria isolated were sub-cultured by re-streaking on blood agar and MSA. Distinct colonies were isolated and stored on nutrient agar slants at $4^{\circ} \mathrm{C}$ in a refrigerator.

For the water samples, $1 \mathrm{ml}$ each was pipetted into a sterile petri dish, thereafter, $20 \mathrm{ml}$ of sterile mannitol salt agar was poured into it using pour plate method. It was then rocked gently to mix and allowed to set. Inoculated agar plate was afterwards opened briefly for 30 seconds in an incubator set at $37^{\circ} \mathrm{C}$, so as to remove condensed water on its surface. Thereafter, covered, inverted and inoculated at $37^{\circ} \mathrm{C}$ for 24 to $48 \mathrm{hrs}$ in the same incubator. Using their colonial appearance such as size, shape, consistency, color, elevation and the differential characteristics such as pigmentation, suspected discrete colonies of $S$. aureus were sub-cultured by re-streaking on nutrient agar plates to obtain a pure culture according to guidelines. ${ }^{22}$ Distinct well-separated yellow colonies and creamy white colonies on MSA and blood agar respectively were picked aseptically and stored on nutrient agar slants at $4^{\circ} \mathrm{C}$ for further biochemical characterization.

Each organism was subjected to some preliminary biochemical tests such as gram staining, catalase, mannitol fermentation, blood heamolysis and slide coagulase test. ${ }^{23}$

\section{Antimicrobial susceptibility testing}

This was determined by the agar diffusion technique as 
recommended by the Clinical Laboratory Standards Institute (CLSI) guidelines ${ }^{24}$ on Mueller-Hinton agar (Oxoid) using the following antibiotic impregnated disks (Abtek Biologicals Ltd): gentamicin $(10 \mu \mathrm{g})$, cefuroxime $(30 \mu \mathrm{g})$, ofloxacin $(5 \mu \mathrm{g})$, cloxacillin $(5 \mu \mathrm{g})$, ceftazidime $(30 \mu \mathrm{g})$, ceftriaxone $(30 \mu \mathrm{g})$, erythromycin $(30 \mu \mathrm{g})$ and augumentin $(30 \mu \mathrm{g})$ for gram positive bacteria. The procedure includes inoculation of stock cultures stored at $4{ }^{\circ} \mathrm{C}$ on nutrient agar slants into $10 \mathrm{ml}$ of nutrient broth which was then incubated overnight at $37^{\circ} \mathrm{C}$. Thereafter, serial dilution of $10^{1}$ into sterile distilled water was carried out. Afterwards, $1 \mathrm{ml}$ of the culture solution was transferred into sterile petri dishes. Thereafter, sterile Mueller-Hinton agar that has been cooled to $55^{\circ} \mathrm{C}$ in water bath was poured into each and allowed to solidify. However, another 1 in 10 dilution factor was also plated out on nutrient agar for each test for determination of viable count so as to know the average number of colony used during the susceptibility tests. Antibiotic sensitivity disc was later placed on one of the solidified Mueller-Hinton plates sterilely and both plates were incubated at $37^{\circ} \mathrm{C}$ in an incubator overnight. Zone of inhibition seen round the antibiotic disc the following day were measured while diameter was categorized as resistant, intermediate and sensitive after comparing with Clinical and Laboratory Standards Institute (CLSI) standard for each bacteria isolate. ${ }^{24}$ Those that were resistant to three or more classes of antibiotics, were classified as multidrug resistant.

\section{Statistical analysis}

The relationship between antibiotic resistant profiles and the sample locations (environmental and clinical) isolates was determined using chi-square two ways contingency table. The Qi Macros statistical software for excel was used for the analysis.

\section{Results}

A total of 150 water samples and 120 clinical samples were collected, out of which 45 and 120 S. aureus organisms were isolated respectively (Table 1).

Table 1: Occurrence of $S$. aureus from drinking water sources in Dutsin-ma

\begin{tabular}{lcc|ccc}
\hline \multicolumn{2}{c|}{ Environmental Isolates } & \multicolumn{3}{c}{ Clinical Isolates } \\
\hline Sources & $\begin{array}{c}\text { Number } \\
\text { of Isolates }\end{array}$ & $\begin{array}{c}\text { Percentage } \\
\text { Occurrence } \\
\mathbf{( \% )}\end{array}$ & Sources & $\begin{array}{c}\text { Number of } \\
\text { Isolates }\end{array}$ & $\begin{array}{c}\text { Percentage } \\
\text { Occurrence } \\
(\mathbf{\%})\end{array}$ \\
\hline Reservoir (Isa-kaita) & 18 & 40 & Skin & 10 & 8.3 \\
Reservoir (Water board) & 8 & 17.5 & Nasal & 72 & 60 \\
Tap (Water board) & 5 & 11.1 & Pus & 15 & 12.5 \\
Tank (Isa-kaita) & 4 & 8.9 & Ear & 8 & 6.7 \\
Borehore (Doctor Campus) & 6 & 13.3 & Wound & 15 & 12.5 \\
Well (Kadangaru) & 4 & 8.9 & & & \\
\hline \multicolumn{1}{c}{ Total } & $\mathbf{4 5}$ & $\mathbf{1 0 0}$ & & $\mathbf{1 2 0}$ & $\mathbf{1 0 0}$ \\
\hline
\end{tabular}


Antibiotics resistant to environmental isolates showed the highest $(100.0 \%)$ resistance to each of cloxacillin (CXC) and augmentin (AUG), the lowest $(48.9 \%$ ) antibiotic resistance was recorded for gentamycin (GEN) (Table 2). The observed resistance for clinical isolates demonstrated the highest (100\%) resistance to each of erythromycin (ERY) and cloxacillin (CXC) with the lowest $(27.5 \%)$ resistance to ofloxacin (OFL) (Table 2). However, the antibiogram profiles conducted on the isolates revealed a significant $(\mathrm{P}<0.05)$ association between both isolates (environmental and clinical) and resistance to antibiotics. Chi-Square analysis can be found on supplementary Table 1.

Table 2: Antibiotic resistance pattern of $S$. aureus from different sources

\begin{tabular}{ccc|cc}
\hline & \multicolumn{2}{c|}{ Environmental Isolates (n= 45) } & \multicolumn{2}{c}{ Clinical Isolates (n= 120) } \\
\hline Antibiotics & $\begin{array}{c}\text { Resistance No } \\
(\%)\end{array}$ & Susceptible No (\%) & Resistance No (\%) & Susceptible No (\%) \\
\hline OFL & $2(5)$ & $45(100)$ & $33(27.5)$ & $87(72.5)$ \\
AUG & $45(100)$ & $0(0)$ & $110(91.2)$ & $10(8.3)$ \\
CAZ & $44(97.8)$ & $1(2.2)$ & $113(94.2)$ & $20(16.7)$ \\
CRX & $44(97.8)$ & $1(2.2)$ & $24(20.0)$ & $7(5.8)$ \\
GEN & $22(48.9)$ & $23(51.1)$ & $29(24.2)$ & $96(80)$ \\
CTR & $36(80.0)$ & $9(20.0)$ & $120(100)$ & $0(0)$ \\
ERY & $41(91.1)$ & $4(8.8)$ & $120(100)$ & $0(0)$ \\
CXC & $45(100)$ & $0(0)$ &
\end{tabular}

CODE: OFL: Ofloxacin, AUG: Augmentin, CAZ: Ceftazidine, CRX: Cefuroxime, GEN: Gentamycin, CTR: Ceftriaxone, ERY: Erythromycin, CXC: Cloxacillin

The study also identified 28 antibiotic resistance patterns. The multiple antibiotic resistance pattern cloxacillin (CXC), erythromycin (ERY), cefuroxime (CRX), augmentin (AUG), ceftazidine (CAZ) was the most frequently observed pattern (Table 3). All isolated $S$. aureus (165) from this studies were multidrug resistant with different antibiotic resistant pattern. 
Table 3: Multiple antibiotic resistance pattern among $S$. aureus isolates from the clinics and environment

\begin{tabular}{llll}
\hline Location & $\begin{array}{l}\text { No. of } \\
\text { antibiotics }\end{array}$ & Multiple antibiotic resistance pattern & $\begin{array}{l}\text { No. of } \\
\text { Isolates }\end{array}$ \\
\hline Clinic & 3 & CXC, ERY, AUG & 5 \\
& 4 & CXC, ERY, CRX, AUG & 7 \\
& CXC, ERY, AUG, CAZ & 2 \\
& CXC, ERY, CRX, CAZ & 2 \\
& CXC, ERY, CRX, AUG, OFL & 4 \\
& CXC, ERY, CRX, AUG, CAZ & 36 \\
& CXC, ERY, CRX, CAZ, GEN & 1 \\
& CXC, ERY, CRX, CAZ, OFL & 7 \\
& CXC, ERY, CRX, AUG, OFL & 3 \\
& CXC, ERY, CRX, AUG, CAZ, GEN & 4 \\
& CXC, ERY, CRX, AUG, CAZ, CTR & 14 \\
& CXC, ERY, CRX, AUG, CAZ, OFL & 9 \\
& CXC, ERY, CRX, AUG, CAZ, GEN & 7 \\
& CXC, ERY, CRX, AUG, CAZ, OFL, CTR & 2 \\
& CXC, ERY, CRX, AUG, CAZ, OFL, GEN & 2 \\
& CXC, ERY, CRX, AUG, CAZ, OFL, CTR & 5 \\
& CXC, ERY, CRX, AUG, CAZ, CTR, GEN & 7 \\
& CXC, ERY, CRX, AUG, CAZ, OFL, CTR, GEN & 3 \\
& AUG, CXC, CRX, ERY & 1 \\
& 4 & AUG, CXC, CAZ, ERY & 1 \\
& AUG, CXC, CRX, CAZ, CTR & 2 \\
& AUG, CXC, CRX, CAZ, ERY & 3 \\
& AUG, CXC, CRX, CAZ, CTR & 2 \\
& AUG, CXC, CRX, ERY, GEN & 1 \\
& AUG, CXC, CRX, CAZ, ERY, GEN, & 3 \\
& AUG, CXC, CRX, CAZ, ERY, CTR & 10 \\
& & AUG, CXC, CRX, CAZ, ERY, CTR, GEN & 22 \\
\hline
\end{tabular}

OFL: Ofloxacin, AUG: Augmentin, CAZ: Ceftazidine, CRX: Cefuroxime, GEN: Gentamycin, CTR: Ceftriaxone, ERY: Erythromycin, CXC: Cloxacillin

\section{Discussion}

Over the past decade, the percentage of $S$. aureus from clinical specimen that are multidrug-resistant has been steadily increasing around the world, ${ }^{25}$ a phenomenon which has affected the timely administration of appropriate choice antibiotics. ${ }^{26}$ Out of 150 water samples collected from 6 drinking water sources in this study, a total of 45 S. aureus were isolated. However, from a total of 120 clinical samples collected across different body sites: skin, nasal cavities, ear, wound and pus, of patients randomly selected from the study area, $120 \mathrm{~S}$. aureus were isolated (Table 1).

Possible reasons for low prevalence of $S$. aureus from the aquatic environment could be due to the pre-treatment process through which the water had undergone, and also due to the fact that the inhabitants of the community have not had constant contact with the water, since $S$. aureus is a normal flora of the body. However, highest $(60.0 \%)$ occurrence of $S$. aureus from nasal cavities, followed by pus $(12.5 \%)$, wound $(12.5 \%)$, skin $(8.3 \%)$ and the least from ear $(6.7 \%)$ were observed among clinical samples. This finding is consistent with other findings which reported highest $(94.0 \%)$ colonization in extranasal site ${ }^{27}$; and also a highest $(46.8 \%),{ }^{28}(65.9 \%)^{29}$ occurrence from pus. However our findings contradict that of some researchers who reported least isolation of $S$. aureus from nasal cavities. ${ }^{1,30}$ The result of this study which revealed a least 
occurrence of $S$. aureus from wound $(12.5 \%)$, skin (8.3\%) and ear $(6.7 \%)$ could be because these samples were collected from wounds which had undergone pre-treatment with antiseptics which had consequently reduced the microbial load on the wound site. This finding is consistent with other literature which reported a least $(8.0 \%)$ colonization from wounds ${ }^{27}$ and no isolation from the ear. ${ }^{1,31}$

Among the water samples, Isa-Kaita's reservoir showed the highest prevalence (40\%) of the isolates, probably due to the constant contact with the inhabitants of the community. On the other hand, Isa Kaita's tank and Kadangaru's well both recorded the least number of isolates $(8.9 \%)$ (Table 1). This findings agree with others who also reported the presence of $S$. aureus in drinking water in the city of Portugal. ${ }^{11}$ Although this high microbial contamination may be due to poor hygiene and sanitary conditions in and near the water sources, ${ }^{32}$ the propinquity of the water sources to dumpsites and latrines is a possible source of contamination. ${ }^{33}$ Unfortunately, this kind of setting is peculiar to the Dutsin-Ma community in Katsina State where this study was carried out.

It is worthy to note that although $S$. aureus is not a bacteria indicator of fecal contamination, its presence in drinking water is of great public health importance. When present in large quantity, $S$. aureus in water intended for human consumption are potential health threats, especially if these strains possess determinants of antibiotic resistance ${ }^{12,18,34}$ as suggested by this study. These resistance genes can be transferred to normal bacteria present in the GIT of the consumers if the genes are present on mobile genetic elements like integrons and its cassette, plasmid, transposon and insertion sequence These have been reported to be the most virulent and multidrug resistant among all of the HPC bacteria recovered from water supplies in South Africa. ${ }^{34}$ They can form biofilms in major distribution channels. This harbors potential waterborne pathogens and can also serve as a reservoir for transferable resistance genes to other potential bacterial species. ${ }^{11,12}$ Moreover, if they eventually cause diseases, treatment will require the administration of antibiotics (usually beta lactams). However, considering how important some of these beta-lactams have become over the years, both as first-line therapy for severe and mild infections, ${ }^{35}$ resistance to them will affect their timely administration, ${ }^{26}$ and this could increase mortality rate, and of course affect the economy. ${ }^{36}$
The result of the antibiogram conducted on clinical isolates, revealed a highest $(100.0 \%)$ resistance to both cloxacillin and erythromycin, followed by cefuroxime $(94.2 \%)$ (Table 2). The least $(20.0 \%)$ resistance was demonstrated against gentamicin. When compared to the samples from drinking water sources, a similar result was obtained. The isolates demonstrated a highest $(100 \%)$ resistance to both cloxacillin and augumentin, followed by cefuroxime (97.8\%) and ceftazidime (97.8\%). The least resistance was demonstrated against ofloxacin $(0.00 \%)$ and gentamicin $(48.9 \%)$ (Table 2). This agrees with other findings which also reported a low $(7.1 \%)$ resistance to gentamicin. ${ }^{37}$ The resistance to the antibiotics tested may be attributed to the production of beta-lactamase, an enzyme that inactivates $\beta$-lactam rings in $\beta$-lactam antibiotics and closely related antibiotics. A similarity in the antibiotic resistance pattern displayed by the isolates could suggest a possible link between the isolates from the clinic and that from the water environment. Therefore, work is ongoing on the molecular typing of these bacteria isolates for any clonal similarities.

Among the clinical isolates, resistance to 5 antibiotic groups $(42.5 \%)$ were the most commonly observed antibiotic resistance pattern, while resistance to 8 groups $(2.5 \%)$ was the least prevalent. On the other hand, the environmental isolates demonstrated highest resistance to 7 groups $(48.9 \%)$ of the antibiotics tested, while a least resistance to 4 groups (4.4\%) was recorded. The multiple antibiotic resistance pattern cloxacillin (CXC), erythromycin (ERY), cefuroxime (CRX), augmentin (AUG), ceftazidine (CAZ) was the most frequently observed pattern (Table 3).

\section{Conclusion}

This study has for the first time, given a comparative insight into the antibiogram study of $S$. aureus isolated from clinical and selected drinking water of Dutsin-Ma town, Katsina State, Nigeria. The findings of this study reveals that Dutsin-Ma water sources are laden with multidrug resistant strains of $S$. aureus. These multidrug resistant $S$. aureus isolated from drinking water may transfer their resistant determinant to bacteria in the gastrointestinal tract (GIT) of consumers if present on mobile genetic elements such as plasmid and transposon, thereby, prolong treatment time and lead to an increase in mortality rate if bacterial infection arise. The result presented in this study may explain, in part, the increasing misuse of an- 
tibiotics, poor hygiene and sanitation practices including human attitudes such as dumping of refuse or untreated sewage in and around this water sources in the study area. This study hereby recommends the provision of potable water, modern sanitary and sewage disposal facilities and creation of awareness to the people in the community, of the risk associated with consumption of contaminatedwater. Also, the results of this study suggests the imperative need to reassess policies on antibiotics use as well as develop new antibiotics to curb the problems posed by resistant strains.

\section{Acknowledgements}

We appreciate the technical support of all the technical staff of the Department of Microbiology, Federal University Dutsin-Ma, Katsina State, Nigeria. Dr. Matouke Moise of Department of Biological Sciences, Baze University, Abuja, Nigeria is also appreciated for volunteering to analysis some of the data statistically.

\section{Financial support}

This research was self-sponsored by the researchers.

\section{Conflict of interest}

None to declare.

\section{Ethical approval}

Not required for water samples collection but was obtained before sampling of clinical samples from human in the hospitals.

\section{References}

1. Adetayo TO, Deji-Agboola AM, Popoola MY, Atoyebi TJ, Egberongbe KJ. Prevalence of methicillin resistant staphylococcus aureus from Clinical Specimens in Ibadan, Nigeria. The International Journal Of Engineering and Science. 2014; 3(9): 1-11

2. Savov E, Gergova I, Borisova M, Kjoseva E, Trifonova A, Todorova I. Consumption of antimicrobial drugs and antibiotic resistance in problematic for hospital infectious pathology bacteria. Trakia Journal of Sciences. 2013;11: 338342

3. Myelotte JM, Tayara A. Staphylococcus aureus bacteremia: predictors of 30-day mortality in a large cohort. Clin. Infect. Dis. 2000; 31: 1170-1174

4. De Kraker MEA, Davey PG, Grundmann H. Mortality and hospital stay associated with resistant Staphylococcus aureus and Escherichia coli bacteremia; estimating the burden of antibiotic resistance in Europe. 2011; PLoS Med. 8:e1001104. doi:10.1371/journal.pmed.1001104

5. Centers for Disease Control andprevention. Antibiotic Resistance Threats in the United States, 508. 2013; Available online at:http://www.cdc.gov/drugresistance/ threat-report-2013/pdf/ar-threats-2013 508.pdf

6. Falagas ME, Karageorgopoulos DE, Leptidis J, Korbila IP. MRSA in Africa: filling the global map of antimicrobial resistance. 2013; PLoS One. 8:e68024. doi:10.1371/ journal.pone.0068024

7. Garza-González E, Dowzicky MJ. Changes in Staphylococcus aureus susceptibility across Latin America between 2004 and 2010. Braz. J. Infect. Dis. 2013; 17: 1319. doi:10.1016/j.bjid.2012.08. 017.

8. Lee BY, Singh A, David MZ, Bartsch SM, Slayton RB, Huang SS. The economic burden of community-associated methicillin-resistant Staphylococcus aureus (CA-MRSA). Clin. Microbiol. Infect. 2013; 19: 528-536.doi: 10.1111/j.1469-0691.2012.03914.x

9. Chen CJ, Huang Y-C. New epidemiology of Staphylococcus aureus infection in Asia. Clin. Microbiol. Infect. 2014; 20: 605-623.doi:10.1111/1469-0691.12705

10. HarakehSH, Yassin H, El-Fadel M. Isolates of Staphylococcus aureus and Saprophyticus resistant to antimicrobials isolated from the Lebanese aquatic environment. Mar. Poll. 2006; 52: 912-919

11. Faria CI, Vaz-Moreira E, Serapicos OCN and Manaia CM. Antibiotic resistance in coagulase negative Staphylococci isolated from waste water and drinking water. Sci. Total Environ. 2009; 407: 3876-3882

12. Abulreesh, Organji SR. The prevalence of multidrug-resistant staphylococci in food and the environment of Makkah, Saudi Arabia. Res. J. Microbiol. 2011; 6 (in press). 13. Allen MJ, Edberg SC, Reasonar DJ. Heterotrophic plate count bacteria - what is their significance in drinking water. Int. J. Food Microbiol. 2004; 92: 265-274.

14. Cheung AL, Projan SJ, Gresham H. The genomic aspect of virulence, sepsis, and resistance to killing mechanisms in Staphylococcus aureus. Curr. Infect. Dis. Rep. 2002; 4: 400-410.

15. Charoenca N, Fujioka RS. Association of staphylococcal skin infections and swimming. Wat. Sci. Technol. 1995; 31: 11-17.

16. Hunter PR. Waterborne Disease: Epidemiology and Ecology. John Wiley \& Sons, Chichester, UK. 1997

17. Ibarluzea J, Moreno B, Zigorraga C, Castilla T, Mar- 
tinez M, Santamaria J. Determinants of the microbiological water quality of indoor swimming-pools in relation to disinfection. Wat. Res. 1998; 32: 865-871

18. Percival SI, Chalmers RM, Em-brey M, Hunter PR, Sellwood J, Wyn-jones P. Microbiology of water borne diseases. Elsevier academic press, San Diego, USA. 2004.

19. News Track India. Retrieved from NEWS TRACK India: https//:www.newstrackindia.com/information/ worldinfo/latitudelongitude/CountryCities/Nigeria/ city-dutsin-ma-1630461.htm. 2015

20. Wikipedia. Dutsin-ma. Retrieved from Wikipedia: https//:en.m.wikipedia.org/wiki/Dutsin-ma. 2014

21. Cheesborough M. District Laboratory Practice in Tropical Countries. Part 2. Cambridge University press, London. 2002; 132-194.

22. Cowan and Steel. Cowan and Steel's Manual for the Identification of Medical Bacteria. 2003; $3^{\text {rd }}$ ed. Ed Barrow GI, Feltham RKA. Pg 331: Cambridge University Press. 1993. ISBN 0-521-32611-7

23. Olutiola PO, Famurewa O, Sonntag HG. An introduction to microbiology, a practical approach. Tertiary textbook series. 2000

24. Clinical and Laboratory Standards Institute (CLSI) antimicrobial susceptibility standards. $M 2-A 9$ and M7-A7. 2007; Vol 27, No 1.

25. Styers D, Sheehan DJ, Hogan P, Sahm DF. Laboratory-based surveillance of current antimicrobial resistance patterns and trends among Staphylococcus aureus: 2005 status in the United States. Ann Clin Microbiol Antimicrob. 2006; 5:2

26. European Food Safety Authority (EFSA). Scientific Opinion on the public health risks of bacterial strains producing extended-spectrum beta-lactamases and/or AmpC beta-lactamases in food and food-producing animals. EFS A Journal. 2011; 9(8): 2322

27. Popovich KJ, Aroutcheva A, Hota B, Beavis KG, Hayden MK, Weinstein RK. Anatomic Sites of Colonization with Community-Associated Methicillin-Resistant S. aureus. Infection Control and Hospital Epidemiology. 2014; 35(9): 1192-1194

28. Bhattacharya S, Bir R, Majumdar T. Evaluation of Multidrug Resistant $S$. aureus and their Association with
Biofilm Production in a Tertiary Care Hospital, Tripura, Northeast India. Journal of Clinical and Diagnostic Research. 2015; 9(9): 1-5

29. Sharma NK, Garg R, Baliga S, Bhat GK. Nosocomial Infections and Drug Susceptibility Patterns in Methicillin Sensitive and Methicillin Resistant $S$. aureus. Journal ofClinical and Diagnostic Research. 2013; Vol-7(10): 2178-2180

30. Rahimi F, Bouzari M. Biochemical Fingerprinting of Methicillin-Resistant $S$. aureus isolated from sewage and hospital in Iran. Jundishapur J Microbiol. 2015; 8(7): e19760, $2-5$

31. Baba J, Inabo HI, Umoh VJ, Olayinka AT. Antibiotic resistance patterns of methicillin-resistant $S$. aureus (MRSA) isolated from chronic skin ulcer of patients in Kaduna state, Nigeria. IOSR Journal of Pharmacy. 2015; 5(2): 07-12

32. Okonko IO, Adejoye OD, Ogunnusi TA. Microbiological and physicochemical analysis of different water samples used for domestic purposes in Abeokuta and Ojota, Lagos State, Nigeria. African Journal of Biotechnology. 2008; 7(5): 617-621.

33. Odeyemi AT, Oluyege JO, Adebayo AA. Antibiogram of isolated bacteria from Omisanjana hand-dug well water and flowing stream: Scientific Journal of Microbiology. 2012; 1(3): 82-90.

34. Pavlov D, de Wet CME, Grabow WOK, Ehlers MM. Potentially pathogenic features of heterotrophic plate count bacteria isolated from treated and untreated drinking water. Int. J. Food Microbiol. 2004; 92: 275-287.

35. Ben-Ami R, Schwaber MJ, Navon-Venezia S, Schwartz D, Giladi M, Chmelnitsky I, Leavitt A, Carmeli Y. Influx of extended-spectrum beta-lactamase-producing Enterobacteriaceae into the hospital. Clin Infect Dis. 2006; 42: 925934.

36. Department of Health, London. UK Five Year antimicrobial Resistance Strategy. 2013-2018. 2013; 7-12.

37. Taddesse Z, Tiruneh M, Gizachew M. S. aureus and it's Antimicrobial Susceptibility Pattern in Patients, Nasal carage of Health Personnel, and objects at Dessie referral hospital, Northern Ethiopia. Global Journal of Medical research: Microbiology and Pathology. 2014; 14 (2): 29-35 